\title{
Anaesthetic Management of an Infant with a tiant Inter-Parietal Meningoencephalocele
}

Avneesh Khare, Neelam Dogra, Avnish Bharadwaj, Priyanka Jain, Raksha Kundal

From the Department of Anaesthesiology, SMS Medical College and Attached Group of Hospitals, Jaipur (Rajasthan), India.

\section{Abstract:}

Meningoencephalocele (MEC) consists of herniation of cerebrospinal fluid (CSF), meninges and brain tissue through a congenital bony defect in the cranium. Anesthetic challenges associated with a giant MEC include proper securing of airway, intra-operative prone position and its complications, accurate assessment of CSF and blood loss, etc. An active, 3 month old, first child from a non-consanguineous marriage with no other congenital anomaly was admitted with a giant inter-parietal MEC. MRI brain revealed a large midline inter-parietal MEC, containing small amount of brain and large volume of CSF. Baby was induced and intubated in supine position and operated upon in prone position. Sudden drainage of large volume of CSF occurred on opening the sac. It was accompanied with bradycardia, which was successfully managed with intravenous injection atropine. Thereafter, intra-operative course remained uneventful. Intraoperative losses were adequately replaced. Recovery from anesthesia was satisfactory and postoperative course was uneventful. After monitoring in ICU for a day, the patient was shifted to the ward and discharged on $10^{\text {th }}$ post-operative day with advice for regular follow up.

Key words: Analgesia, Anesthesia, Neuromuscular blockage, Prone position, Bradycardia, Meninges.

\section{Introduction}

Meningoencephalocele (MEC) is a type of neural tube defect which is characterized by herniation of cerebrospinal fluid (CSF), meninges and brain tissue through a congenital bony defect in the cranium [1]. The size of a MEC may be variable and has a bearing with its successful anesthetic management $[2,3]$. A giant MEC, which may be even larger than the head from which it arises can pose several anesthetic challenges including proper securing of airway, prone position for surgery, accurate assessment of CSF and blood loss, etc. [4,5]. We report a case of giant inter-parietal MEC and discuss its anesthetic implications.

\section{Case Report}

A 3 month old female, first child from a nonconsanguineous marriage, delivered by caesarean section, presented to our institute with a huge, gradually enlarging, cystic midline swelling in the

\section{Corresponding Author: Dr. Avneesh Khare}

Email: avneeshkhare@gmail.com

Received: March 12, 2014 | Accepted: May 5, 2014 | Published Online: May 30, 2014

This is an Open Access article distributed under the terms of the Creative Commons Attribution License (creativecommons.org/licenses/by/3.0)

Conflict of interest: None declared | Source of funding: Nil | DOl: http://dx.doi.org/10.17659/01.2014.0045 
inter-parietal region. The child was weighing $5 \mathrm{~kg}$, moving all four limbs equally, accepting feeds, and there was no other obvious congenital anomaly. Family history was insignificant.

On examination, the swelling was much larger than head size, tense and cystic [Fig.1]. Transillumination test was positive. MRI brain revealed a large bony defect in midline showing herniation of brain parenchyma along with CSF and venous sinuses [Fig.2]. Interhemispheric fissure and ventricular cavity were not well formed. Midline structures appeared to be fused, while posterior fossa structures appeared normal. Possibility of encephalomyelocele with holoporencephaly could not be ruled out.

Cardiac and respiratory system examination did not reveal any abnormality. Routine laboratory investigations revealed $\mathrm{Hb}$ of $12.1 \mathrm{gm} / \mathrm{dL}$, adequate platelets and normal liver and renal function tests. The child was taken up for surgery under general anesthesia after obtaining an informed written consent from his parents. Temperature of the operation theatre was maintained. Preoperative pulse rate and blood pressure were $120 \mathrm{bpm}$ and $90 / 60 \mathrm{~mm} \mathrm{Hg}$, respectively. After attaching pulse oximeter and stethoscope for monitoring purpose, injection atropine $25 \mu \mathrm{g}$ and injection fentanyl

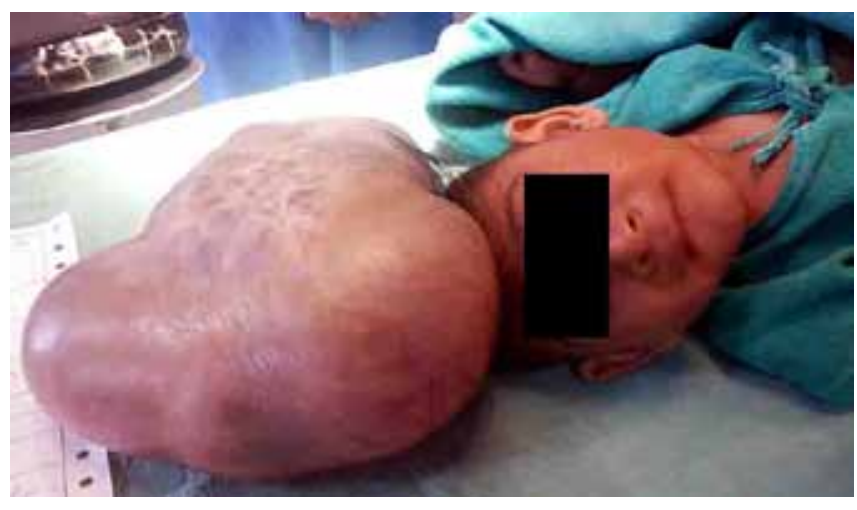

Fig.1: A 3 month old child with giant interparietal meningoencephalocele.
$5 \mu \mathrm{g}$ were given intravenously. Anesthesia was induced in supine position with titrated doses of injection thiopentone (total dose used was $25 \mathrm{mg}$ intravenous), given slowly via serial dilution. After ensuring adequate bag and mask ventilation with $100 \% \quad \mathrm{O}_{2}$, injection succinylcholine $10 \mathrm{mg}$ intravenously was used to facilitate intubation. Laryngoscopy was attempted by a senior anesthesiologist using Miller's blade no. 1 and it revealed a Cormack-Lehane grade $2 \mathrm{~B}$. Patient was successfully intubated using a $3.5 \mathrm{~mm}$ ID uncuffed ET tube in first attempt. $60 \mathrm{mg}$ paracetamol was administered rectally for postoperative analgesia. After ensuring proper placement and securing of tube, the patient was turned to prone position for surgery [Fig.3]. It was ensured that there was no pressure on the abdomen due to bolsters and all pressure points were adequately padded. ECG electrodes, temperature probe and NIBP monitoring were attached. One extra intravenous line with 24G cannula was secured. Anesthesia was maintained with $\mathrm{N}_{2} \mathrm{O}: \mathrm{O}_{2}-50: 50$ and halothane 0.2-1\%. Intermittent intravenous boluses of injection atracurium were used to provide muscle relaxation. On opening the sac, there was sudden drainage

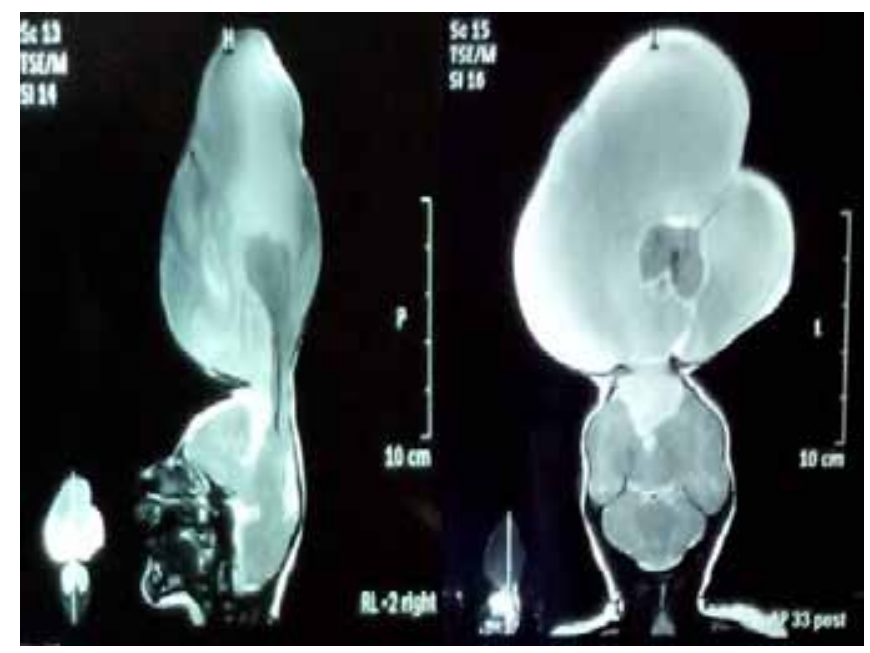

Fig.2: MRI scans showing a large bony defect in midline with herniation of brain parenchyma and CSF. 
of approximately $1200 \mathrm{~mL}$ CSF [Fig.4]. Sudden bradycardia was noted and it was successfully managed with intravenous injection atropine. Thereafter, intra-operative course remained uneventful with vital parameters being within normal limits. The sac was excised completely and dura was closed after excision of herniated glial tissue. Blood loss was $70-90 \mathrm{~mL}$. Intraoperatively, $60 \mathrm{~mL}$ intravenous fluids (Isolyte P) and $50 \mathrm{~mL}$ blood were given. The surgical procedure was completed in 2 hours. Neuromuscular blockade was reversed with intravenous injection neostigmine and injection atropine. The child was shifted to recovery room for monitoring, and was extubated after 30 minutes on return of gag reflex and adequate limb movements. The patient was then shifted to ICU, where she started crying and accepting feeds on the same day. Postoperative course remained uneventful and she was discharged after 10 days with advice for regular follow up.

\section{Discussion}

'Cephalocele' is a broad term, representing extracranial extension of intracranial structures through a defect in the skull and dura. A cephalocele may be classified as any one of the four types, i.e. meningoencephalocele, meningocele, atretic encephalocele and gliocele [1]. The reported incidence in the Western world is 1 to 3 per 10000 live births, while it is slightly higher in Southeast Asia, with approximately 1 in 5000 live births [1].

Meningoencephalocele (MEC), a type of cephalocele, consists of a herniation of CSF, meninges and brain tissue through the skull defect [1]. Prenatal diagnosis on an encephalocele can be done by ultrasonography (USG), maternal serum alpha fetoprotein (MSAFP) and amniocentesis [2]. Various other congenital anomalies may also be associated with MEC, like club foot, exostrophy bladder, prolapsed uterus, Klippel-Fiel Syndrome, cleft palate and congenital cardiac defects $[5,6]$.

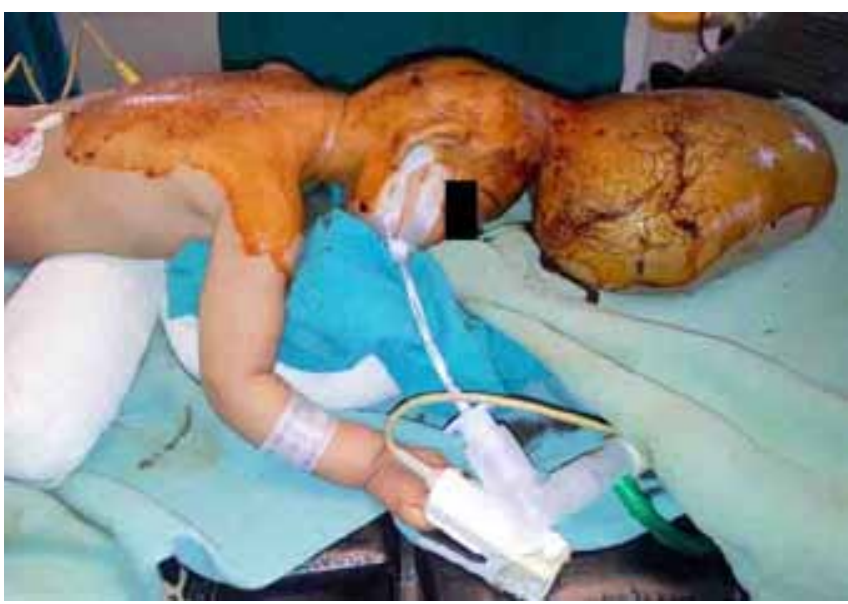

Fig.3: Prone positioning of the patient for surgery.

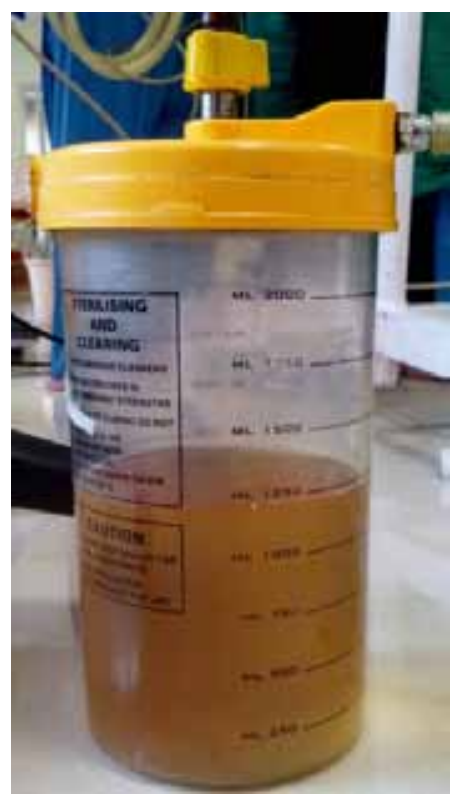

Fig.4: CSF drained from the swelling on opening the sac.

One of the major challenges in patients with a giant MEC posted for surgical excision is proper securing of the airway. Options include mask ventilation and intubation in lateral position [5], in supine position with sac placed on a 'doughnut' shaped support/ bolsters $[5,7]$ or by bringing the child to the edge 
of the table so that entire swelling lies below the table top with an assistant supporting it temporarily [2]. In our patient, none of these above mentioned measures were required, as the swelling was in midline and not extending occipitally. Bag mask ventilation (BMV) and intubation were successfully achieved in supine position itself. As such patients are candidates for difficult BMV and intubation, it is imperative to ensure adequate BMV before injecting any muscle relaxant to facilitate intubation [1]. Use of nasotracheal/ armoured endotracheal tubes has also been advocated to prevent kinking of tube in prone position [7]. However, we could not do so due to non-availability of such tubes.

Temperature regulating mechanism in these patients may be defective due to lack of central autonomic control $[4,6]$. Also, there is more heat loss due to large exposed surface area. So, adequate measures for conservation of body temperature should be taken. While turning to prone position, care should be taken that patient's abdomen remains free from bolsters, so that ventilation is not affected and venous return is not compromised. Also, all pressure points should be padded adequately [4]. There is always a chance of significant bleeding in these cases; therefore, adequate amount of blood should be arranged before proceeding for surgery. Also, intensive intraoperative hemodynamic monitoring coupled with high degree of suspicion and correct estimation with adequate replacement of losses is imperative for successful anaesthetic management $[4,5]$. Care should be taken that CSF from the swelling is decompressed in a slow controlled manner [8]. Sudden loss of large volumes of CSF may result in bradycardia and sudden cardiac arrest [2]. In our patient, there was sudden drainage of approximately $1200 \mathrm{~mL}$ of CSF on opening the sac, which resulted in bradycardia and was successfully managed. Thereafter, intraoperative course remained uneventful.

Due to change in CSF dynamics, there may be postoperative hydrocephalus, for which ventriculoperitoneal shunt may be required $[2,8]$. Other potential complications include cranial nerve palsy which may result in inspiratory stridor [4], lack of pharyngeal coordination, poor suckling reflex, absent gag reflex, aspiration complications, or derangement in pontomedullary respiratory control center leading to inadequate spontaneous respiration even after complete reversal of muscle relaxation [1]. Overall prognosis of MEC cases is poor and depends on contents, sac size, operability, hydrocephalus and other associated malformations $[3,4,8]$.

\section{Conclusion}

Successful anaesthetic management of a case of giant MEC consists of anticipation with proper management of difficult airway, proper intra operative prone positioning and correct estimation coupled with adequate replacement of intra operative losses.

\section{References}

1. Cevik B, Orskiran A, Yilmaz M, Ekti Y. Anesthetic management of a newborn with giant occipital meningoencephalocele: Case report. International Journal of Case Reports and Images 2012;3(8):10-12.

2. Singh H, Singh D, Sharma DP, Tandon MS, Ganjoo $P$. Perioperative challenges in patients with giant occipital encephalocele with microcephaly and micrognathia. J Neurosci Rural Pract. $2012 ; 3(1): 68-70$.

3. Singh N, Rao PB, Ambesh SP, Gupta D. Anaesthetic Management of a Giant Encephalocele: Size Does Matter. Pediatr Neurosurg 201 2;48:249252.

4. Joshi K, Srivastava U, Chand T, Kumar A. Giant Occipital Meningoencephalocele: case report and review of literature. Anaesthesia Update $2011 ; 14(2): 35-37$. 
5. Singh K, Garasia M, Ambardekar M, Thota R, Dewoolkar L, Mehta K. Giant Occipital Meningoencephalocele:Anaestheticlmplications. The Internet Journal of Anesthesiology. 2006 Volume 13 Number 2.

6. Creighton RE, Relton JE, Meridy HW. Anaesthesia for occipital encephalocoele. Can Anaesth Soc
J. 1974;21:403-406.

7. Charles J Cote. Pediatric Anesthesia. In: Miller's Anesthesia $7^{\text {th }}$ Ed. Volume 2: 2589.

8. Mohapatra R, Panigrahi MK, Kumari P. An interesting case of interparietal encephalocele J Pediatr. Neurosci. $2011 ; 6(2): 155-156$. 